\title{
An atypical arrhythmia
}

\author{
A. A. M. Wilde
}

Published online: 9 April 2013

(C) The Author(s) 2013. This article is published with open access at Springerlink.com

A 58-year-old male presented with palpitations, which he had experienced occasionally in the past years, but this time it did not stop. His ECG at presentation is shown in Fig. 1. Physical examination revealed no abnormalities. Figure 2 shows an enlargement of leads I, II and III at a different point in time. What is your diagnosis?

Fig. 2 An enlargement of leads I, II and III at a different point in time

\section{Fig. 1 ECG at presentation \\ Fig. 1 ECG at}

\section{Answer}

You will find the answer elsewhere in this issue.

Open Access This article is distributed under the terms of the Creative Commons Attribution License which permits any use, distribution, and reproduction in any medium, provided the original author(s) and the source are credited.
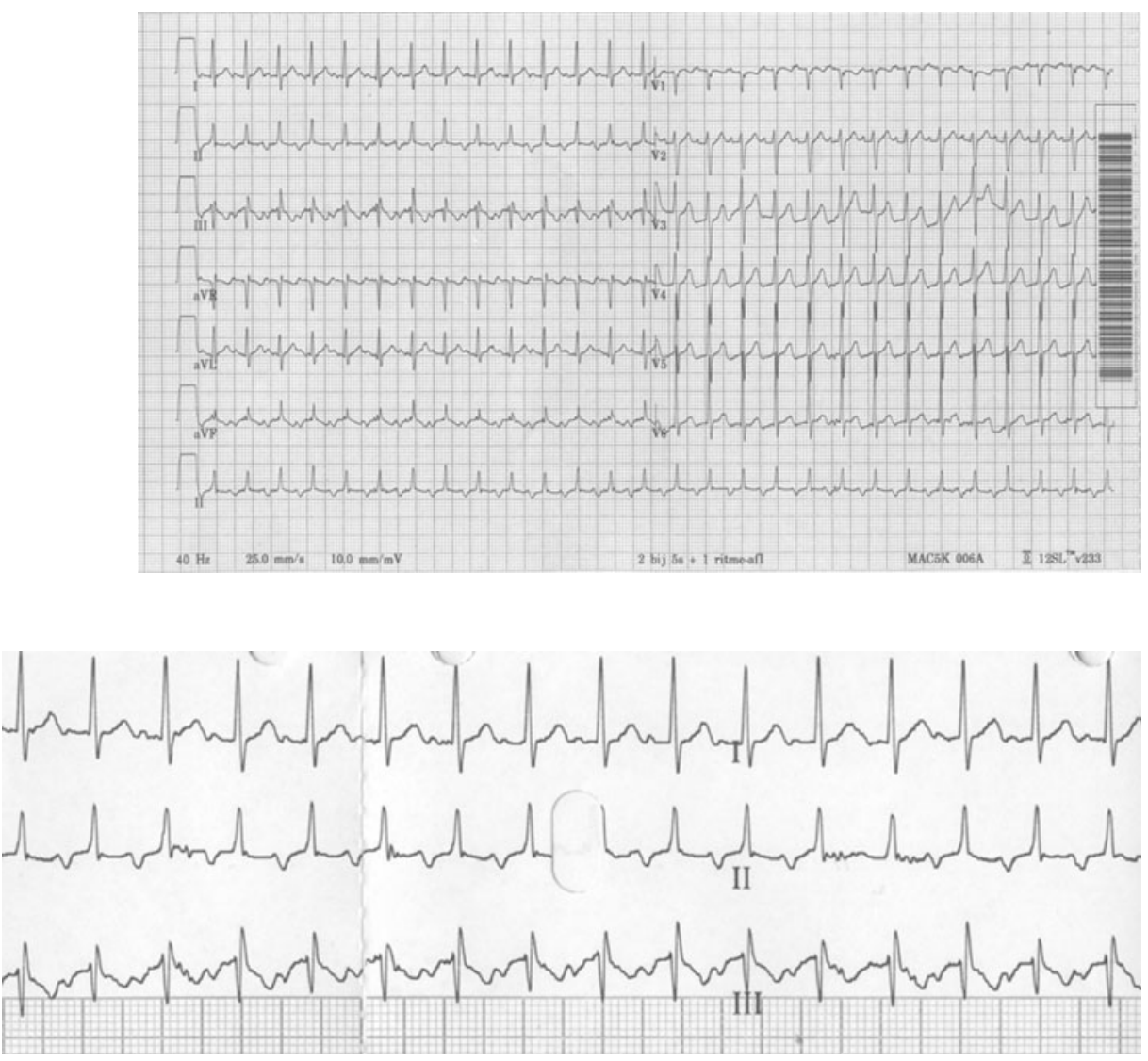

A. A. M. Wilde $(\triangle)$

Cardioloog AMC Amsterdam, Department of Cardiology,

Academic Medical Centre, Meibergdreef 9,

1105 AZ Amsterdam, the Netherlands

e-mail: a.a.wilde@amc.uva.nl 